\title{
Near Infrared Reflectance Spectroscopy (NIRS) for determination of chemical entities of natural pasture from Ethiopia
}

\author{
Dereje Fekadu ${ }^{1}$, Seyoum Bediye, Aemiro Kehaliw, Tadesse Daba, Getu Kitaw and \\ Getnet Assefa \\ ${ }^{1}$ Ethiopian Institute of Agricultural Research (EIAR), Holetta Research Center, P.O.Box 31, \\ Holetta, Ethiopia
}

\begin{abstract}
In the mixed crop-livestock farming system of Ethiopia, natural pasture production is related to seasonal rainfall distribution which is restricted to only a few months of the year. Livestock owners in this country experience periods of excess forage in the rain season where preserving it through haymaking became tradition as a strategy for the periods of scarcity, particularly the dry season of a year. Forage can also be stored as standing hay, the cheapest way of conserving forage, in a place like pastoral and agro-pastoral production system where a decline in quality can be tolerated. Mixed grass-legume pasture samples from different agro-ecology were collected and portion of the samples were analyzed conventionally to determine their chemical composition (dry matter, ash, crude protein, neutral detergent fiber, acid detergent fiber, lignin) and in vitro dry matter digestibility to validate the NIRS calibration. NIRS was evaluated by the coefficient of determination in calibration $\left(R^{2}\right)$, standard error of calibration (SEC), and standard error of cross validation (SECV). The results showed NIRS is extremely useful for predicting nutrient contents as compared to conventional chemical analysis methods which are not difficult to conduct, but they are expensive in terms of time and resources.
\end{abstract}

Keywords: Chemical composition, dry season feed, natural pasture, NIRS, Nutritive value

\section{INTRODUCTION}

Pasture production is usually related to seasonal rainfall distribution which in Ethiopia is restricted to only a few months of the year. Consequently livestock owners who rely exclusively on pastures experience periods of excess forage in the rain season followed with periods of scarcity in the dry season. In the mixed crop-livestock farming system haymaking is tradition, preserving wet-season herbage.

Forage can also be stored as standing hay in a place where a decline in quality can be tolerated, mostly practiced in pastoral and agro-pastoral production system. This is generally the cheapest way of conserving forage. Standing hay may be conserved, usually on fenced grazing land, by leaving areas ungrazed during the preceding part of the growing season. It can then be utilized during the dry season when forage from other areas is no longer available in adequate quantities.

The need for research on the quality of forage species available, appropriate techniques for cutting, drying and storing the hay, and the socio-economic viability of such technologies come to be emphasis.
Near infrared reflectance spectroscopy (NIRS) is one of the recent techniques being applied for such feed resource quality determination and further characterization. The method has been applied for various feed stuffs and parameters and the application for characterization both for ruminant and non ruminant animals have been studied extensively in the temperate environment (Gordon et al., 1998; Stuth et al., 2003; and White and Rouvinen-Watt, 2004). The technique is, thus far, noted to be one of the robust applications to estimate chemical entity and parameters like digestibility and degradability which are usually estimated by bioassays. The robustness of the method has in general improved over the years as a result of improved instrumentation, standardization across laboratories and more importantly because of the ability to relate spectral regions to relevant chemical characteristics. This research meant to backup the above mentioned efforts in these production systems with the following objectives:

- Assess the potential of NIRS in characterizing nutritive value, its predictive capacity on the natural pasture, and standardize the method in the laboratory 


\section{MATERIAL AND METHODS}

Samples from different sites grazing pasture of Ethiopia (mixed grass-legume pasture from different agro-ecology) were collected.

Conventional analysis for determination of chemical entities dry matter (DM), Ash, crude protein (CP), neutral detergent fiber (NDF), acid detergent fiber (ADF) and lignin, and bio-availability i.e. in vitro organic matter digestibility (IVOMD) of the samples was carried. Chemical analysis for determination of DM, Ash, and CP used procedures of AOAC (2004) and determination of NDF, ADF, and Lignin using procedure Goering and Van Soest (1970). In vitro digestibility determined using the two-stage rumen fluid-pepsin technique (Tilley and Tery, 1963).

The samples from grazing pasture of Ethiopia were analyzed using conventional analysis which are then be used to calibrate the NIRS apparatus for further use in the procedure for predicting more samples from pasture fields. The samples were ground to pass through a $1 \mathrm{~mm}$ sieve size and 3 grams of each sample were scanned by NIRS at $1108-2492 \mathrm{~nm}$, with an $8 \mathrm{~nm}$ step. Before scanning the samples predried at $60^{\circ} \mathrm{C}$ overnight in an oven to standardize moisture conditions. The spectra of each sample were taken by scanning. Mathematical and statistical treatments of the NIRS spectra were first treated using ISI. Average spectra for each sample were obtained from the scanning. Calibration equations were calculated by step-wise multiple linear regressions on the samples and 30 samples for each feed type used for validation purposes.

The correlation of predicted and conventionally determined values used to assess the reliability of NIRS and residual behavior were predicted. Regression analysis of the predicted values and conventionally determined values were also undertaken to assess the precision of NIRS.

\section{RESULTS}

The feed samples used for calibration and validation (> 100 and 30 samples respectively) valued in their chemical entities (DM, Ash, CP, NDF, ADF and lignin) and bio-availability (IVOMD) shown in table 1 where the ranges of each entity shown being similar to previously observed values (Seyoum et al., 2007). Furthermore, the predicted values for each trait were similar to the values obtained based on conventional chemical analyses. Regarding bio-availability, the reference values for in vitro was widely spread (SEC $=4.12)$ and show strong relationship $\left(r^{2}=0.82\right)$ with the NIRS values. The scatter plots showed the relationship between NIRS predicted values versus data results from conventionally analysis methods for $\mathrm{CP}$ and in vitro Fig 1 and 2.

Table 1. Values of coefficient of determination, standard errors of calibration and standard errors of crossvalidation obtained from the NIRS calibration of natural pasture

\begin{tabular}{|l|l|l|l|l|l|l|}
\hline Parameters/traits & $\mathbf{n}$ & Range (\%) & $\mathbf{R}^{2}$ & SEC & 1-VR & SECV \\
\hline DM & 109 & $89.5-95.2$ & 0.84 & 0.70 & 0.35 & 0.77 \\
\hline Ash & 109 & $6.21-10.9$ & 0.86 & 0.73 & 0.08 & 0.74 \\
\hline CP & 106 & $1.98-10.0$ & 0.83 & 0.92 & 0.39 & 1.05 \\
\hline NDF & 109 & $52.1-79.4$ & 0.79 & 4.44 & 0.36 & 4.62 \\
\hline ADF & 109 & $28.4-50.4$ & 0.75 & 2.95 & 0.19 & 3.29 \\
\hline Lignin & 107 & $2.62-8.49$ & 0.77 & 0.66 & 0.39 & 0.77 \\
\hline In vitro & 109 & $42.8-78.5$ & 0.82 & 4.12 & 0.24 & 5.20 \\
\hline
\end{tabular}

$\mathrm{R}^{2}=$ coefficient of determination in calibration

SEC $=$ standard error of calibration

1-VR = coefficient of determination of cross validation

SECV $=$ error of cross validation 


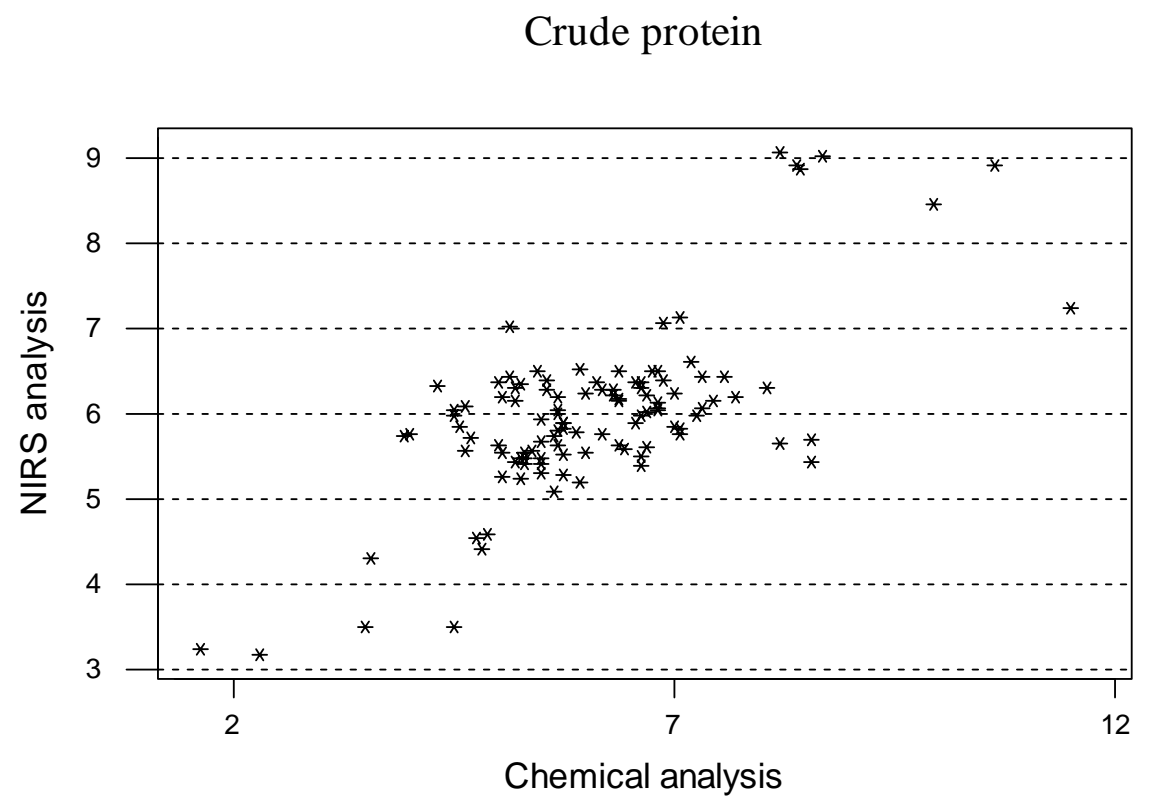

Fig 1. Relationship between results from chemical analysis and results of NIRS data's of CP from natural

In vitro

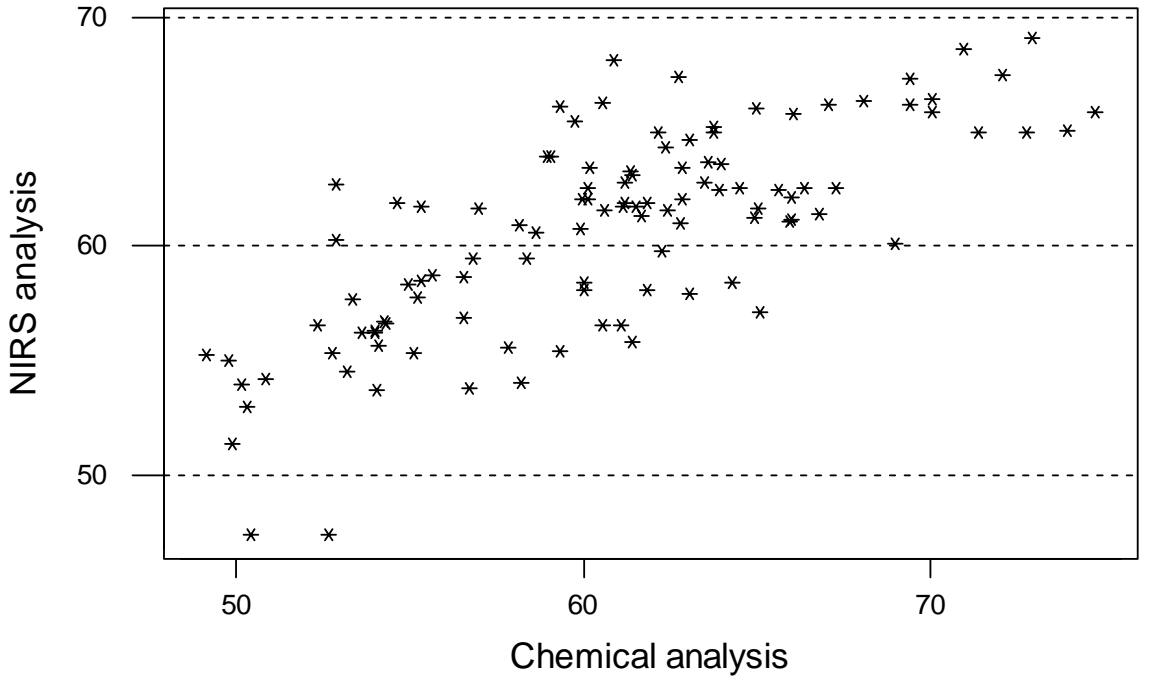

Fig 2. Relationship between results from chemical analysis and results of NIRS data's of in vitro from natural pasture 
Thus, the best performance in calibration equations for individual traits corresponded to those traits for which the variability in the calibration set was wider, indicating that successful calibration equations using NIRS depend on the variability of constituents under investigation.

\section{DISCUSSION}

The calibration and external validation statistics for the natural pasture and its traits were considered in this study. The calibration equations for DM, Ash, CP and Lignin have shown relatively high coefficient of determination $\left(\mathrm{R}^{2}\right)$, and low standard errors of calibration (SEC) and standard errors of crossvalidation (SECV) and hence, these traits could be predicted with good precision. Higher SEC value was recorded for the traits (NDF, ADF and in vitro) of feed sample may be due to the broader range of variation in the trait of respective sample.

SECV is a basic statistics to measure accuracy for a calibration equation (Shenk and Westerhaus, 1993). Accordingly, the calibration error should be comparable to the sampling error and this value is similar to standard error of performance (SEP). Ideally, the scatter plot should contain data points distributed evenly about the line but within the confidence limits as observed for most traits in the present study.

Hence, the NIRS showed promise for measuring the parameters/traits considered and its use is extremely useful for predicting nutrient contents as compared to conventional chemical analysis methods which are not difficult to conduct, but they are expensive in terms of time and resources. Further research, thus, should aim to improve continuously the accuracy of the NIRS prediction by adding a broader range of samples to each of the traits from different regions of the country and years to the calibration set.

\section{REFERENCES}

AOAC (1990). Official Method of Analysis, $15^{\text {th }}$ edn. Association of Official Analytical Chemists, Arlington, USA.

Goering, H. K. and van Soest, P. J (1970). Forage Fibre Analysis. USDA, ARS Agric. Handbook, No. 379, pp. 1 -12 .

Gordon, F.J., Cooper, K.M., Park, R.S., and Steen, R.W.J (1998). "The prediction of intake potential and organic matter digestibility of grass silages by near infrared spectroscopy analysis of undried samples", Animal Feed Science and Technology, 70: 339 - 351.

Seyoum Bediye, Zinash Sileshi and Dereje Fekadu (2007). Chmical Composition and Nutritive Values of Ethiopian Feeds. Research paper 73, Ethiopian Institute of Agricultural Research, 2007. ISBN 978-99944-53-17-7. pp 24.

Shenk, J. S. and Westerhaus, M. O (1993). "Analysis of agriculture and food products by Near Infrared Reflectance Spectroscopy", ISI Monograph. 116 pp.

Stuth, J., Jama, A. and Tolleson, D (2003). "Direct and indirect means of predicting forage quality through near infrared reflectance spectroscopy", Field Crop Research 84:45 - 56. www.elsevier.com/locate/fcr

Tilley, J. A. and Tery, R. A (1963). "A two-stage technique for the in vitro digestion of forage crop", Journal of British Grassland Society, 18, $104-111$.

White, M. and Rouvinen-Watt, K (2004). "Near - infrared evaluation of wet mink diets", Animal Feed Science and Technology, 111, $239 \quad$ - 246. www.elsevier.com/locate/anifeedsci 